\title{
Capacity Limitations of brine Contamination on High Density Oil- Based Drilling Fluid
}

\author{
Shuanggui $\mathrm{Li}^{1,2}$, Sheng Fan ${ }^{1,2}$, Jiaxue $\mathrm{Li}^{3 *}$, Yingting $\mathrm{Li}^{1,2}$, Biao Qi ${ }^{1,2}$ and Junwei Fan ${ }^{1,2}$ \\ ${ }^{1}$ Key Laboratory of Enhanced Recovery for Fracture-Cave Oil Reservoir, Xinjiang, China \\ ${ }^{2}$ Sinopec Northwest Oilfield company, Xinjiang, China \\ ${ }^{3}$ China University of Petroleum (Beijing) @ Karamay, Xinjiang, China
}

\begin{abstract}
Aimed on the problem that the Drilling fluids were easily intruded by the saline water in highpressure salt-gypsum formations, and the properties of the drilling fluid were damaged and accidents easily occur. The mechanism of drilling fluid contamination by the formation brine was analyzed and the capacity limits of the contamination were found out. The results show that small amount of brine invasion causes emulsification while large amount of brine invasion lead to demulsification. Two capacity limitations were proposed. The first limitation is $10 \%$ of saline water concentration, below which the performance of the drilling fluid remains relatively good. The second limitation is $30 \%$ of saline water concentration, below which the drilling fluid needs to be systematically maintained, and after which the fluid has no potential for maintenance. This proposal has been successfully used in 8 wells in Kuqa foreland area, and the drilling cycle was saved by 35 days on average.
\end{abstract}

\section{Introduction}

In DB, KS, BZ and other blocks of Tarim basin, a large number of salt gypsum layers are developed, in which high-pressure salt water are developed between the layers. During drilling, a lot of salt water and other salts will invade or dissolve into the drilling fluid due to the high-pressure salt water layer, which will damage the coalescence stability of the drilling fluid itself, deteriorate the performance of the drilling fluid, and even cause accidents such as sticking, seriously affecting the drilling safety ${ }^{[1.2]}$. Table 1 Statistics of salt water encountered during drilling in $\mathrm{DB}, \mathrm{KS}, \mathrm{BZ}$ and other blocks of Tarim basin in recent five years.

Table 1. Brine overflow in Tarim basin from 2011 to 2015.

\begin{tabular}{|c|c|c|c|c|}
\hline well & $\begin{array}{c}\text { Lost } \\
\text { circulation } \\
\text { times }\end{array}$ & $\begin{array}{c}\text { Brine } \\
\text { overflow } \\
\text { times }\end{array}$ & $\begin{array}{c}\text { Blocking } \\
\text { times }\end{array}$ & $\begin{array}{c}\text { Other } \\
\text { truble } \\
\text { times }\end{array}$ \\
\hline DB5 & 13 & 1 & 42 & \\
\hline DB206 & 6 & 3 & 17 & \\
\hline DB303 & 6 & 2 & & \\
\hline DB304 & 22 & 1 & 28 & 2 \\
\hline DB306 & 17 & 4 & 11 & \\
\hline KS7 & 11 & 1 & 40 & 1 \\
\hline KS2-1-4 & 1 & 2 & 11 & \\
\hline KS2-1-11 & 4 & 1 & 30 & \\
\hline KS2-1-18 & 17 & 4 & 15 & \\
\hline BZ101 & 14 & 1 & 44 & 12 \\
\hline
\end{tabular}

High density oil-based drilling fluid $(2.45-2.60 \mathrm{~g} / \mathrm{cm} 3)$ is generally used in this block due to large oil-bearing salt gypsum layer. When drilling with high-pressure brine, the invasion performance of drilling fluid will become worse, which will lead to complex drilling truble such as blocking and sticking. However, the mechanism of brine invasion and the capacity limit of high-density oil-based drilling fluid affected by brine invasion are not clear, which can not effectively guide drilling operation. Therefore, the laboratory experiments and mechanism analysis are used to improve the understanding of the mechanism and capacity limit of brine contamination of drilling fluid, and to guide the field operation.

\section{Mechanism of brine invasion}

In order to study the mechanism of oil-based drilling fluid contaminated by salt water, a certain amount of salt water is added to the oil-based drilling fluid commonly used in the field, and its performance is measured. According to the change of performance, the influence mechanism of the oil-based drilling fluid on the drilling fluid is analyzed. The experimental oil-based drilling fluid system was taken from ks2-1-4 well with a sampling depth of $5546 \mathrm{~m}$. The drilling fluid is: diesel oil $+2 \%-3 \%$ main emulsion $+2 \%-3 \%$ secondary emulsion $+0.5 \%-0.8 \%$ organic soil $+0.3 \%-0.6 \%$ suspending agent $+1.5 \%-2.5 \%$ duratone + barite.

\subsection{Performance effect of salt water addition on into oil based drilling fluid}

The oil-based drilling fluid was soaked with $5 \%, 10 \%$, $15 \%, 20 \%, 30 \%, 40 \%, 50 \%$ and $60 \%$ brine by volume to test its influence on the rheology property. The experimental results are shown in Fig. 1 and Fig. 2.

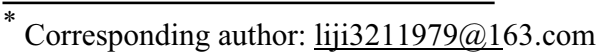




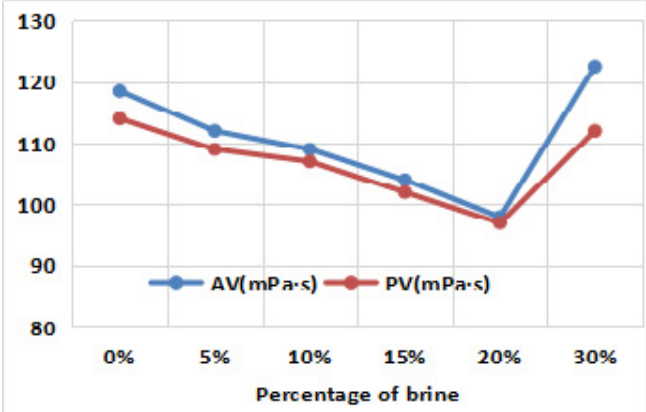

Fig. 1 Effect of different percentage of brine on viscosity of oil-based drilling fluid

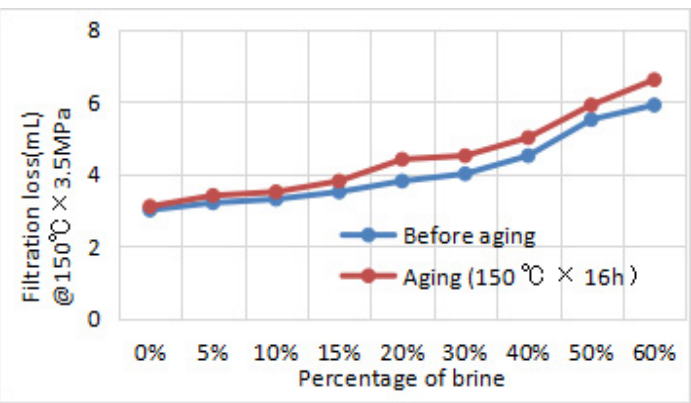

Fig. 2 Effect of different percentage of brine on filtration loss of oil-based drilling fluid

The results show that when the brine percentage is less than $20 \%$, the viscosity decreases with the increase of brine percentage; When the percentage of brine is more than $30 \%$, the viscosity increases, and the percentage of brine is more than $50 \%$, the viscosity of the system has exceeded the measurement range of the instrument.The High temperature and high pressure filtration loss increased slowly with little rate.

\subsection{Effect of brine on settlement stability of oil- based drilling fluid system}

Due to the contamination of brine, the settlement stability of high-density oil-based drilling fluid is bound to be affected, and the settlement stability is one of the important parameters to be concerned after the drilling fluid is contaminated by brine ${ }^{[3.4]}$. In order to determine the effect of brine contamination on the settling stability of drilling fluid, a steel cylinder with inner diameter of $6.35 \mathrm{~cm}$, outer diameter of $7.6 \mathrm{~cm}$, inner clear height of $35 \mathrm{~cm}$, total height of $39 \mathrm{~cm}$ and volume of $1107 \mathrm{ml}$ was used to simulate the wellbore. The contaminated drilling fluid settles in the steel cylinder, and the steel cylinder is heated by the incubator to keep the drilling fluid at a certain temperature. After a certain settling time, the upper and lower parts drilling fluid of the steel cylinder are taken respectively to measure their density. Then the density difference between the upper and lower parts is used to reflect the settling stability of the drilling fluid at different temperatures. The settling stability of oil-based drilling fluid at temperature of $120{ }^{\circ} \mathrm{C}$ and $150{ }^{\circ} \mathrm{C}$ after adding $5 \%, 10 \%, 15 \%, 20 \%, 30 \%, 40 \%, 50 \%$ and $60 \%$ brine was tested. The test results are shown in Fig. 3.

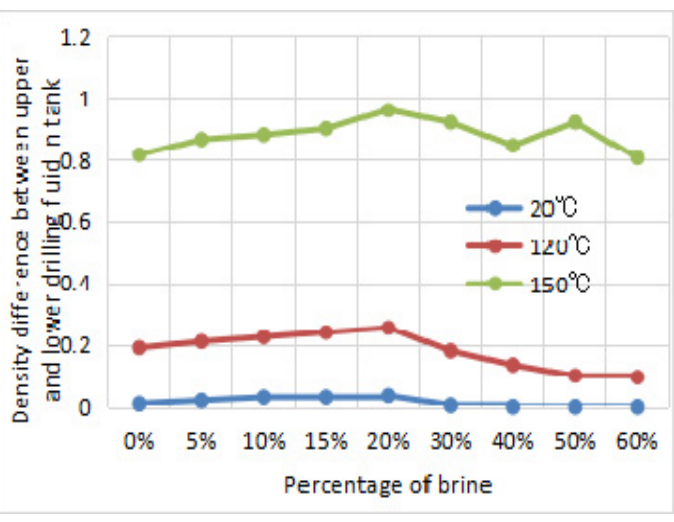

Fig. 3 Effect of different percentage of brine on settling stability of oil-based drilling fluid

The results in Fig. 3 show that the density difference of drilling fluid first increases and then decreases with the increase of brine percentage; With the increase of temperature, the settling stability of the drilling fluid decreases, the performance of the oil-based drilling fluid has become worse at $150{ }^{\circ} \mathrm{C}$, and more clear fluid is precipitated from the upper part

\subsection{Eeffect of brine on demulsification voltage}

Demulsification voltage is one of the indexes of oilbased drilling fluid stability [5]. The demulsification voltage of $0 \%, 5 \%, 10 \%, 15 \%, 20 \%, 30 \%, 40 \%, 50 \%$ and $60 \%$ brine was tested. The test results are shown in Table 2.

Table 2 Relationship between percentage of brine and demulsification voltage of oil based drilling fluid

\begin{tabular}{|c|c|c|}
\hline $\begin{array}{c}\text { percentage } \\
\text { of } \\
\text { brine( } \%)\end{array}$ & $\begin{array}{c}\text { Demulsification } \\
\text { voltage of drilling } \\
\text { fluid after ageing(v) }\end{array}$ & $\begin{array}{c}\text { Demulsification } \\
\text { voltage of drilling } \\
\text { fluid after ageing (v) }\end{array}$ \\
\hline 0 & 468 & 445 \\
\hline 5 & 396 & 410 \\
\hline 10 & 340 & 380 \\
\hline 15 & 225 & 305 \\
\hline 20 & 180 & 295 \\
\hline 30 & 175 & 263 \\
\hline 40 & 150 & 225 \\
\hline 50 & 121 & 180 \\
\hline 60 & 90 & 143 \\
\hline
\end{tabular}

The experimental results in Table 2 show that the demulsification voltage decreases gradually after adding brine, and it slightly increased after ageing $\left(150{ }^{\circ} \mathrm{C}, 16\right.$ h).

\section{4 influence of brine on lubricity and filter cake of oil-based drilling fluid}

The lubrication coefficient was tested when the salt water dosage was 5\%, 10\%, 15\%, 20\%, 30\%, 40\%, 50\% and $60 \%$,the test results are shown in Table 3 . The mud cake measured in the experiment is shown in Figure 4.

Table 3 Relationship between brine percentage and lubricity of oil based drilling fluid system

\begin{tabular}{|c|c|c|c|c|c|c|c|}
\hline $\begin{array}{c}\text { percentage } \\
\text { of brine } \\
(\%)\end{array}$ & 0 & 10 & 20 & 30 & 40 & 50 & 60 \\
\hline $\begin{array}{c}\text { Lubricity } \\
\text { of drilling } \\
\text { fluid } \\
(\mathrm{KF})\end{array}$ & 0.075 & 0.094 & 0.138 & 0.152 & 0.170 & 0.191 & 0.217 \\
\hline
\end{tabular}




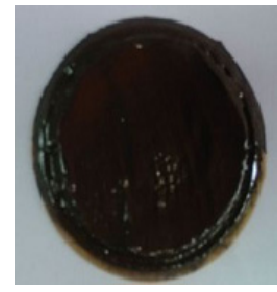

$10 \%$ brine

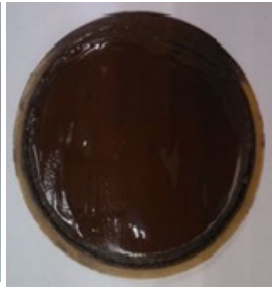

$30 \%$ brine

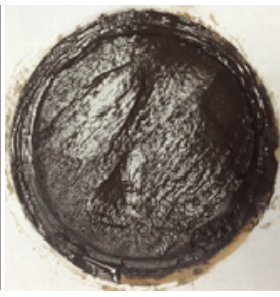

$50 \%$ brine
Fig.4 Mud cake of drilling fluid with different brine percentage

The data in Table 3 and Figure 4 show that with the increase of salt water dosage, the filter cake tends to thicken, resulting in the increase of lubrication coefficient, but the overall lubricity is still good.

\subsection{Mechanism of brine invasion into oil based drilling fluid}

The effects of brine addition on the rheological properties, settling stability, filtration loss, demulsification voltage, filter cake and lubricity of oilbased drilling fluid system are analyzed. The pollution mechanism of brine to oil-based drilling fluid is as follows:

1)When a small amount $(\leq 20 \%)$ of brine is invaded into oil-based drilling fluid, the viscosity decreases slowly and the filtration loss increases slowly. The system still has a high demulsification voltage, which indicates that the immersed brine and the excessive emulsifier in the system form a relatively stable emulsion.

2)When a large amount ( $>20 \%)$ of brine is invaded into the oil-based drilling fluid system, the stability of the emulsion is broken, and the viscosity and filtration loss continue to increase, which indicates that the brine enters the oil-based drilling fluid in the form of water phase, reduces the oil-water ratio of the system, increases the viscosity of the oil-based drilling fluid, and worsens the mud cake.

3)When the volume of brine in the system increases to more than $30 \%$, the viscosity and filtration loss increase a lot, but it is still water in oil emulsion. When the actual experiment reaches $60 \%$, the system is demulsified. Therefore, the possibility of wetting reversal is relatively small in actual drilling.

\section{Research on the capacity limit of drilling fluid and maintenance}

According to the mechanism of brine contamination on drilling fluid, combined with the actual requirements of drilling in KS, DB and BZ blocks of Tarim basin, the key performance indexes of oil-based drilling fluid are selected. According to the performance changes and maintenance after brine contamination, the capacity limit of drilling fluid contaminated by brine is determined to guide the field drilling fluid performance maintenance.

\section{1 index of drilling fluid contaminated by brine}

Combined with the influence and mechanism of brine on the rheological properties, filtration rate, temperature resistance and sedimentation stability of drilling fluid system, the first capacity limit is determined by the fact that the drilling fluid can be used in the well after simple treatment, and the second capacity limit is the end point of maintenance treatment, which means that the performance of drilling fluid has been damaged over that, the amount of drilling fluid by maintenance treatment has increased a lot, the treatment cost is large. According to the actual drilling performance of oil-based drilling fluid, demulsification voltage, Gel strength of 10 minute and apparent viscosity are selected as indexes to divide the capacity limit of brine invasion. The results are shown in Table 4.

\begin{tabular}{|c|c|c|c|}
\hline Table 4 Invasion capacity limit index \\
\begin{tabular}{|c|c|c|c|}
\hline index & $\begin{array}{c}\text { demulsification } \\
\text { voltage } \\
(\mathrm{V})\end{array}$ & $\begin{array}{c}\text { Gel strength of } \\
10 \text { minute } \\
(\mathrm{Pa})\end{array}$ & $\begin{array}{c}\text { apparent } \\
\text { viscosity } \\
(\mathrm{mPaS})\end{array}$ \\
\hline $\begin{array}{c}\text { first capacity } \\
\text { limit }\end{array}$ & $>400$ & $\leqslant 8$ & $100 \sim 120$ \\
\hline $\begin{array}{c}\text { second } \\
\text { capacity limit }\end{array}$ & $400 \sim 260$ & $8 \sim 15$ & $<100$ \\
\hline
\end{tabular}
\end{tabular}

\subsection{Invasion capacity limit of oil-based drilling fluid}

According to the capacity limit index, the key performance of drilling fluid is divided. If the index value of drilling fluid is still within the design range after contamination, it is recorded as the safe area (blue). There is not much beyond the design range, the index value can be adjusted to the design range as the warning area (yellow) after simple treatment. Those that may lead to drilling accidents and complications are classified as dangerous areas (red), from which the salt water invasion amount and drilling fluid safety chart are drawn, as shown in Table 5.

Table 5 Safety chart of drilling fluid by brine Invasion

\begin{tabular}{|c|c|c|c|c|}
\hline $\begin{array}{c}\text { percentage } \\
\text { of } \\
\text { brine( \%) }\end{array}$ & $\begin{array}{c}\text { Gel strength } \\
\text { of 10 } \\
\text { minute(Pa) }\end{array}$ & $\begin{array}{c}\text { apparent } \\
\text { viscosity } \\
(\mathrm{mPaS})\end{array}$ & $\begin{array}{c}\text { demulsification } \\
\text { voltage } \\
\text { (V) }\end{array}$ & $\begin{array}{c}\text { Lubricity of } \\
\text { drilling fluid } \\
\mathrm{KF}\end{array}$ \\
\hline $0 \%$ & 5.5 & 118.5 & 445 & 0.075 \\
\hline $5 \%$ & 6 & 112 & 410 & 0.081 \\
\hline $10 \%$ & 7 & 109 & 380 & 0.094 \\
\hline $15 \%$ & 5.5 & 104 & 305 & 0.125 \\
\hline $20 \%$ & 6 & 98 & 295 & 0.138 \\
\hline $30 \%$ & 6 & 122 & 263 & 0.152 \\
\hline $40 \%$ & 9 & 133 & 225 & 0.170 \\
\hline
\end{tabular}

According to the chart of oil-based drilling fluid, the capacity limit of oil-based drilling fluid polluted by brine is determined, as shown in Table 6.

Table 6 Invasion capacity limit of oil based drilling fluid

\begin{tabular}{|c|c|c|}
\hline $\begin{array}{c}\text { capacity } \\
\text { limit }\end{array}$ & $\begin{array}{c}\text { percentage of } \\
\text { brine } \\
(\%)\end{array}$ & Key points of maintenance \\
\hline First & $<10 \%$ & $\begin{array}{c}\text { Add weighting materials and } \\
\text { adjust density }\end{array}$ \\
\hline Second & $<30 \%$ & $\begin{array}{c}\text { Adding treatment agent and } \\
\text { maintaining performance }\end{array}$ \\
\hline
\end{tabular}




\subsection{Maintenance and treatment of drilling fluid polluted by brine}

In the experiment, $30 \%$ brine was Invased, diesel oil, emulsifier, organic soil, suspending agent and other treatment agents were added, and their properties were determined, as shown in Table 7. The formula of drilling fluid is oil base drilling fluid $+30 \%$ brine $+100 \%$ diesel oil $+1.5 \%$ main emulsion $+1.5 \%$ secondary emulsion + $0.9 \%$ organic soil $+0.3 \% \mathrm{SC}+1.5 \%$ fluid loss additive + barite in Table 7 .

Table 7 maintenance of fluid polluted by $30 \%$ brine

\begin{tabular}{|c|c|c|c|c|c|c|}
\hline condition & $\begin{array}{c}\mathrm{AV} / \\
\mathrm{mPa} . \mathrm{s}\end{array}$ & $\begin{array}{c}\mathrm{PV} / \\
\mathrm{mPa} . \mathrm{s}\end{array}$ & $\begin{array}{c}\mathrm{YP} / \\
\mathrm{Pa}\end{array}$ & $\begin{array}{c}\mathrm{Gel} \\
\mathrm{Pa}\end{array}$ & $\begin{array}{c}\mathrm{HTHP} \\
150^{\circ} \mathrm{C} \\
\mathrm{mL} / \mathrm{mm}\end{array}$ & $\begin{array}{c}\text { demulsificati } \\
\text { on voltage } \\
\text { (V) }\end{array}$ \\
\hline $\begin{array}{c}\text { Before } \\
\text { aging }\end{array}$ & 113 & 102 & 11 & $6 / 7$ & $3.2 / 2$ & $/$ \\
\hline $\begin{array}{c}\text { After } \\
\text { aging }\end{array}$ & 117 & 107 & 10 & $6.5 / 8$ & $3.0 / 2$ & 565 \\
\hline
\end{tabular}

For the oil-based drilling fluid system with $30 \%$ salt water, $100 \%$ diesel oil, $1.5 \%$ main emulsion, $1.5 \%$ secondary emulsion, $0.9 \%$ organic soil, $0.3 \%$ suspending agent and $1.5 \%$ fluid loss additive are used for maintenance. The $\mathrm{pH}$ value is adjusted to 9 and the original density is increased. The performance of the system is restored to the same level as that of the field drilling fluid.

\section{Conclusions}

1)The main mechanism of salt water immersion in dirty oil-based drilling fluid is as follows: when a small amount of salt water is immersed in dirty oil-based drilling fluid $(\leq 20 \%)$, the viscosity decreases slowly, and the system still has a high demulsification voltage, indicating that the immersed salt water forms a relatively stable emulsion; When a large amount of brine intrudes into the oil-based drilling fluid system, the brine enters into the drilling fluid in the form of water phase to reduce the oil-water ratio.

2)According to the performance of drilling fluid, the demulsification voltage, final shear value, apparent viscosity and lubricity of oil-based drilling fluid are determined as the key indexes. According to the influence of brine on the key indexes, the first and second capacity limits of high-density oil-based drilling fluid are determined to be $10 \%$ and $30 \%$, within the first capacity limit, simple treatment (weighting) is enough, In the second capacity limit, the treatment agent needs to be added for treatment and maintenance. If it exceeds the second capacity limit, the treatment cost is too large, and it is of great significance to treat the polluted water.

3)For the drilling fluid within the second capacity limit, diesel oil, emulsifier, organic soil, suspending agent and other treatment agents should be added in proportion and increased to the original density, so that the performance of the drilling fluid can be restored to the same level as that of the original field drilling fluid.

\section{Acknowledgments:}

This paper is one of the phased achievements of Karamay science and technology project "quantitative evaluation system of drilling fluid plugging based on wellbore stability of hard and brittle shale formation (No. 2020CXRC0019)" . I would like to express my sincere thanks to the Karamay science and Technology Bureau, who funded me in the course of writing this paper.

\section{References}

1. Yin D., Ye Y., Li L.,et al. High pressure salt water treatment technology of well Keshen7 in foothill structural Zone of Tarim [J].Drilling fluid and completion fluid. 2012,29(5):6-8.

2. Li J., Zhao J., Yang H.,et al. The research and application of safe controlled drilling in evaporite salt layer of Missan oilfield [J]. Journal of Yangtze university(Nat sci edit). 2013,10(16):92-94.

3. Shen W., Yin D., Wang Z., et al. Sedimentation Stability of Organic Salt Drilling Fluid [J]. Chemistry and Bioengineering.2016,33(5):56-58.

4. Wang J., Peng F., Xu T., et al .Research Progress on Testing and Predicting Methods for Settling Stability of Drilling Fluid [J].Drilling fluid and completion fluid. 2016,29(5):79-63.

5. Zhang Y., Xiong H., Ding F., al .Impact of water/oil ratio on the rheological of oil based drilling fluid [J]. Science technology and Engineering. 2016,16(12):238-242.

6. Li J., Huang J., Luo P., et al. Technology of controlling loss by drilling in slugging for fracture formation $[\mathrm{J}]$. Journal of Basic Science and Engineering. 2011, 19(5):1-6.

7. Wang G., Pu X., Discrete element simulation of granular lost circulation material plugging a fracture [J]. Particulate Science and Technology. 2014, 32(2):112-117.

8. Zhu B., Tang H., Wang X., et al. Coupled CFDDEM simulation of granular LCM bridging in a fracture. [J] Particulate Science and Technology. 2019, 38(03):371-380. 